\title{
Spectrum of epilepsy - prevalence, impact, and treatment gap: an epidemiological study from Al-Quseir, Egypt
}

This article was published in the following Dove Press journal:

Neuropsychiatric Disease and Treatment

12 May 2016

Number of times this article has been viewed

\author{
Hamdy N El-Tallawy' \\ Wafaa M Farghaly' \\ Tarek A Rageh' \\ Ghaydaa A Shehata' \\ Nabil A Metwally ${ }^{2}$ \\ Reda Badry' \\ Mohammed A Sayed ${ }^{3}$ \\ Ahmed M Abdelwarith ${ }^{2}$ \\ Mahmoud R Kandil' \\ Mohamed A Hamed' \\ Khaled O Mohamed' \\ Amal M Tohamy' \\ 'Department of Neurology, Assiut \\ University, Assiut, ${ }^{2}$ Department of \\ Neurology, Faculty of Medicine, \\ Al-Azhar University - Assiut Branch, \\ Assiut, ${ }^{3}$ Department of Neurology, \\ Sohag University, Sohag, Egypt
}

Correspondence: Ghaydaa A Shehata Department of Neurology and Psychiatry, Assiut University Hospital, Assiut, Egypt

$\mathrm{Tel}+20882314031$

Fax +20882333327

Email ghaydaa83@yahoo.com
Background: Epidemiology continues to be an important research tool in the study of epilepsy and related disorders, providing a better understanding of the frequency, causes, and natural history of the disorder.

Objective: To estimate the prevalence of epilepsy in Al-Quseir, Red Sea Governorate, Egypt, and its magnitude of treatment gap.

Methods: The study was part of a door-to-door study, including every door, to screen all inhabitants in Al-Quseir (33,818 inhabitants) by three specialists of neurology and 15 female social workers (for demographic data collection) using a standardized screening questionnaire. All suspected cases were subjected to detailed history, clinical examination, and electroencephalogram. Neuroimaging studies and estimation of serum drug level were done in select cases if needed.

Results: The study revealed that the lifetime prevalence rate of epilepsy in Al-Quseir is $5.5 / 1,000$, with the highest peak during early childhood, while that of active epilepsy is $3.3 / 1,000$ population. The annual incidence rate is $48 / 100,000$, and the age-specific incidence rate has a U-shaped pattern with two peaks of incidence in early infancy and elderly life. Localizationrelated epilepsy is the most frequently encountered type (58.8\%). The treatment gap of epilepsy in Al-Quseir is $83.8 \%$.

Conclusion: The lifetime prevalence of epilepsy in Al-Quseir city, Red Sea Governorate, was $5.5 / 1000$.

Keywords: epidemiology, epilepsy, treatment gap, Egypt, Al-Quseir, epidemiology

\section{Introduction}

Epilepsy is the most common serious neurological disorder worldwide. ${ }^{1}$ It affects all age-groups and crosses all geographic boundaries; although this distressing condition remits in some people, many will have epilepsy throughout their lives. ${ }^{2}$

Epidemiology continues to be an important research tool in the study of epilepsy and related disorders, providing a better understanding of the frequency, causes, and natural history of the disorder. ${ }^{3}$

The lifetime prevalence of epilepsy in Al Kharga district was 6.76/1,000, and the highest peak was during early childhood. Active epilepsy was 4.99/1,000 population. The annual incidence rate was 43.14/100,000, and age-specific incidence rate has a U-shaped pattern with two peaks of incidence at early infancy and elderly life. The treatment gap of epilepsy in New Valley was similar to that in developing countries $(61.5 \%) .{ }^{4}$

So, in this research, we aimed to study the epidemiology of epilepsy, evaluate its impact on the patient's life, and estimate the magnitude of treatment gap of epilepsy in Al-Quseir, Red Sea Governorate, Egypt. 


\section{Patients and methods Population}

All inhabitants $(33,818)$ who lived in Al-Quseir for at least 6 months at the time of interview were included in this study. The number of inhabitants who refused to participate in this study was $533(1.6 \%)$.

\section{Ethical considerations}

Written informed consent was obtained from each patient prior to participation in the study. Consent of children and elderly personnel was obtained from their caregivers or the family members responsible. Furthermore, the study was approved by the ethical committee of Assiut University and the Ministry of health.

In this study, we aimed to assess the prevalence rate of epilepsy per 1,000 among all inhabitants in Al-Quseir.

\section{Statistical analysis}

Data analysis was carried out by using SPSS version 16 (SPSS Inc., Chicago, IL, USA), Excel (Microsoft Corporation, Redmond, WA, USA), and EpiCalc 2000 (Microsoft Corporation, Redmond, WA, USA).

\section{Methodology}

This study was part of a door-to-door survey (including every door) that was carried out to assess the epidemiology of major neurological disorders ${ }^{5}$ in Al-Quseir. It was conducted by 15 female social workers for collection of socio-demographic data as well as a key person who is well known by the population in this area to facilitate acceptance and participation in this study.

Information source was via a direct personal interview with all inhabitants. Data about children and elderly people were obtained from their caregivers or the family members responsible. Case finding passed through the following stages.

\section{First stage: screening}

All inhabitants of Al-Quseir were screened by using a standardized Arabic questionnaire. ${ }^{5}$ All households ( $n=33,285$; 7,497 families) and both sexes, with $49.4 \%$ males $(n=16,428)$ and $50.6 \%$ females $(n=16,857)$, were screened. A standardized questionnaire, the sensitivity and specificity of which are $96 \%$ and $93.2 \%$, respectively, ${ }^{3}$ was applied by three neurologists to every member of each family (children and elderly were questioned through their caregivers) ${ }^{6}$ to pick up any suspected case of epilepsy.
Sensitivity and specificity of the questionnaire were $96 \%$ and $93.2 \%$, respectively. ${ }^{5}$

\section{Second stage: establishing diagnosis}

Any subject who responded positively to any question of the questionnaire was considered a suspect to have epilepsy and was invited to attend Al-Quseir General Hospital to be evaluated by detailed history taking, detailed description of seizure semiology, as well as pre- and postictal symptoms from near witness. Then, they were subjected to full neurological and physical evaluation by another four staff members of neurology with specific training in recognition and treatment of epilepsy to confirm the diagnosis.

\section{Third stage: investigations}

All cases with epilepsy were subjected to an electroencephalogram and psychometric assessment of intelligence quotient (IQ) using a standardized and validated Arabic version, ${ }^{7}$ the Stanford-Binet test (version IV). ${ }^{8}$ The standardized, valid Arabic version ${ }^{7}$ of the Stanford-Binet scale (4th edition) ${ }^{8}$ was used to assess IQ. Total IQ was classified according to $\mathrm{Melika}^{7}$ into mentally retarded, including those with IQ $\leq 67$, slow learner (IQ $=68-78$ ), below-average intelligence (IQ =79-88), average intelligence (IQ =89-110), aboveaverage intelligence (IQ $=111-120$ ), excellent intelligence (IQ =121-131), and genius (IQ=132).

Neuroimaging (computed tomography and/or magnetic resonance imaging) for suspected structural/metabolic cases, video-electroencephalogram (for suspected multiple types of seizure semiology or pseudo-seizures), and estimation of serum level of antiepileptic drugs were done when indicated.

\section{Inclusion criteria}

- Any age of both sexes.

- A patient is considered to have epilepsy if he or she fulfilled the operational definition proposed by International League Against Epilepsy (ILAE) 9 as "two or more unprovoked seizures occurring at least 24 hours apart."

- Patients with epilepsy were considered to have active epilepsy if they have had their most recent seizure within the previous 5 years or who are currently being treated for epilepsy.

- Classification of seizures types was done according to the commission of classification and terminology of the $\mathrm{ILAE}^{10}$ into presumed genetic, structural/metabolic, and epilepsy of unknown cause. This classification was based on data regarding age at onset, cognitive and developmental antecedents and consequences, motor and sensory 
Table I Age-specific lifetime prevalence and incidence rates of epilepsy in Al-Quseir

\begin{tabular}{|c|c|c|c|c|c|}
\hline \multirow{2}{*}{$\begin{array}{l}\text { Age-group } \\
\text { (years) }\end{array}$} & \multirow[t]{2}{*}{ Total population } & \multicolumn{2}{|c|}{ Lifetime prevalence } & \multicolumn{2}{|l|}{ Incidence } \\
\hline & & Total cases & Prevalence/I,000 (95\% CI) & Cases/year & Incidence/ I 00,000 (95\% Cl) \\
\hline Birth to $<2$ & $\mathrm{I}, 242$ & 15 & I2.I (7.0-20.3) & 4 & $322(296.2-349.0)$ \\
\hline 2 to $<6$ & 2,975 & 32 & $10.8(7.5-15.3)$ & 3 & $100.8(99.8-101.0)$ \\
\hline 6 to $<12$ & 3,862 & 29 & $7.5(5.1-10.9)$ & 2 & $51.7(50.1-53.3)$ \\
\hline 12 to $<18$ & 4,014 & 33 & $8.2(5.8-11.7)$ & 1 & $24.9(23.6-26.3)$ \\
\hline 18 to $<40$ & 13,009 & 40 & $3.1(2.2-4.2)$ & I & $7.6(7.15-8.07)$ \\
\hline 40 to $<60$ & 6,077 & 20 & $3.3(2.86-3.78)$ & 2 & $32.9(31.72-34.10)$ \\
\hline$\geq 60$ & 2,106 & 13 & $6.2(5.20-7.31)$ & 3 & I42.4 (| 27.9-|58.2) \\
\hline Total & 33,285 & 182 & $5.5(5.23-5.72)$ & 16 & $48(47.46-48.54)$ \\
\hline
\end{tabular}

Abbreviation: $\mathrm{Cl}$, confidence interval.

examination and electroencephalogram features, and pattern of seizure semiology and relation to sleep.

\section{Exclusion criteria}

- Refusal to participate in our project (533 subjects $=1.6 \%$ ).

- Patients proved to have acute symptomatic seizures (seizures in close temporal association with acute systemic, metabolic, substance abuse, and with acute CNS insults).

- Febrile seizures.

- Any individual who had only a solitary unprovoked seizure.

\section{Adequate epilepsy treatment}

Any patient with active epilepsy regularly using appropriate antiepileptic drugs as monotherapy or polytherapy at standard dosage was considered having adequate epilepsy treatment. ${ }^{11-13}$

\section{Treatment gap}

Treatment gap is the number of patients with active epilepsy, not on treatment, or inadequately treated, expressed as a percentage of the total number of people with active epilepsy? ${ }^{14}$

\section{Results}

In all, 182 cases were reported to have two or more unprovoked seizures at some point during their lives, with a lifetime prevalence rate of epilepsy of 5.5/1,000 population. Sixteen new cases of epilepsy were recorded during the year of the study with a total incidence rate of $48 / 100,000$ population/year (Table 1). Sex distribution among patients with epilepsy (PWE) is described in Table 2. The most common type of epilepsy was localization-related epilepsy with (58.8\%); other percentages are described in Table 3. Description of education preschool was 47 out of 4,217 (25.8\%), illiterate 66/5,178 (36.3\%), primary school $40 / 9,485(22 \%)$, secondary $27 / 9,183$ (27\%), and university $2 / 5,210(1.1 \%)$. The occupation of PWE was 16/6,473 (8.8\%) housewives, students 45/7,424 (24.7\%), do not work 86/7,874 (47.3\%), mental work 6/3,804 (3.3\%), physical work 12/6,201 (6.6\%), work-related to heavy metals 9/391 (4.9\%), and retired 8/1,118 (4.4\%).

Different types of epilepsy were described in Table 3, as the first was idiopathic then structural and lastly metabolic type. Different etiologies and rates are described in Table 4. Perinatal complications were the most encountered cause of structural, metabolic cases. It was higher during early infancy

Table 2 Sex-specific lifetime prevalence rate of epilepsy in Al-Quseir

\begin{tabular}{|c|c|c|c|c|c|c|}
\hline \multirow{3}{*}{$\begin{array}{l}\text { Age-groups } \\
\text { (years) }\end{array}$} & \multicolumn{2}{|c|}{ Total population (n) } & \multicolumn{4}{|c|}{ Cases } \\
\hline & \multirow[t]{2}{*}{ Male } & \multirow[t]{2}{*}{ Female } & \multicolumn{2}{|c|}{ Male } & \multicolumn{2}{|c|}{ Female } \\
\hline & & & No & Prevalence & No & Prevalence \\
\hline Birth to $<2$ & 637 & 605 & 9 & 14.1 & $6 *$ & 9.9 \\
\hline 2 to $<6$ & $\mathrm{I}, 546$ & $\mathrm{I}, 429$ & 18 & 11.6 & $14^{*}$ & 9.8 \\
\hline 6 to $<12$ & 2,025 & $\mathrm{I}, 837$ & 21 & 10.4 & $8 *$ & 4.4 \\
\hline 12 to $<18$ & 2,065 & 1,949 & 18 & 8.7 & $15^{*}$ & 7.7 \\
\hline 18 to $<40$ & 6,300 & 6,709 & 29 & 4.6 & $\mathrm{II} *$ & 1.6 \\
\hline 40 to $<60$ & 3,021 & 3,056 & 10 & 3.3 & $10 *$ & 3.3 \\
\hline$\geq 60$ & 1,263 & 843 & 10 & 7.9 & $3^{*}$ & 3.6 \\
\hline Total & 16,857 & 16,428 & 115 & 6.8 & 67 & 4.1 \\
\hline
\end{tabular}

Note: The * indicates not significant. 
Table 3 Rate of different types of epilepsy in Al-Quseir

\begin{tabular}{|c|c|c|c|c|}
\hline \multirow[t]{3}{*}{ Type } & \multicolumn{4}{|l|}{ Etiology } \\
\hline & Presumed genetic & Structural/metabolic & Unknown & Total \\
\hline & $n=114(\%)$ & $\mathrm{n}=\mathbf{5 8}(\%)$ & $n=10(\%)$ & $\mathrm{n}=182(\%)$ \\
\hline Generalized & $46(25.3)$ & $26(14.3)$ & $3(1.6)$ & 75 (4I.2) \\
\hline Localization related & $68(37.4)$ & $32(17.6)$ & $7(3.8)$ & $107(58.8)$ \\
\hline Total & $114(62.7)$ & $58(31.9)$ & $10(5.4)$ & $182(100.0)$ \\
\hline
\end{tabular}

(12.1/1,000), gradually decreased during late childhood and early adult life, and increased again to reach its second peak of $(6.2 / 1,000)$ during elderly life; different presentation of seizures are described in Table 5. Approximately a fourth (28\%) of PWE had comorbidity with mental retardation (Table 6). The rate of active epilepsy was 111/182 (64\% patients) with a prevalence of 3.3/1,000 and treatment gap (83.8\%) (Tables 7 and 8).

\section{Discussion}

In the absence of existing code data and health care systems and when services are under-resourced, direct population surveys stand as the gold standard source of data collection for epidemiological studies. This is specifically true particularly when data are collected from all members of the population (both health and nonhealth seeking individuals), and when relevant data are obtained by specialists through direct personal interviews.

Epilepsy accounts for $27 \%$ of all neurological diagnoses and is associated with a substantial burden on physical and mental health. ${ }^{15}$

Epidemiology continues to be an important research tool in the study of epilepsy and related disorders, providing a better understanding of the frequency, causes, and natural history of the disorder. Moreover, beyond risk factors and seizure prognosis, epidemiological studies advance knowledge of many other aspects of epilepsy. ${ }^{3,16}$ However, accurate estimates of incidence and prevalence are difficult to achieve because identifying people who may have epilepsy is difficult. ${ }^{17}$

It was frequently reported that the prevalence of epilepsy tends to be lower in developed countries $(4.3-7.5 / 1,000)$ and remarkably higher in developing countries $(17-57 / 1,000){ }^{18,19}$

However, the recorded lifetime prevalence of epilepsy in Al-Quseir was 5.5/1,000, lying within the range reported in developed countries and similar to that recorded in New York $(5.2 / 1,000){ }^{20}$

However, it is less than that recorded by Khedr et $\mathrm{al}^{21}$ in Assiut who screened 6,498 inhabitants and revealed a prevalence rate of $12.67 / 1,000$.

This low lifetime prevalence rate, similar to that recorded in developed industrialized countries, could be attributed to the lower rate of new incident cases plus loss of unresolved cases of elderly people with epilepsy. Furthermore, it may be due to the low incidence of symptomatic epilepsy due to CNS infections. The wide variability in the rates is partially caused by geographical and medico-social differences. ${ }^{9}$ However, a considerable part of the variation may be explained by different case-finding techniques and dissimilar inclusion criteria. ${ }^{22}$

Another explanation may be due to the structural nature of population in Al-Quseir which is formed of migrants of different Nile valley governorates. So, genetic causes and inherited types of epilepsy are lower than that in Nile valley and this could explain the low incidence of the presumed genetic epilepsy.

Table 4 Rate and prevalence of probable etiologies of epilepsy in Al-Quseir

\begin{tabular}{llll}
\hline Etiology & No of cases & \% of PWE (n=182) & Prevalence/ I,000 N=33,385 \\
\hline Presumed genetic & 114 & 62.6 & 3.4 \\
Structural/metabolic & 58 & 31.8 & 1.75 \\
$\quad$ Perinatal complications & 31 & 17 & 0.9 \\
$\quad$ Vascular & 12 & 6.6 & 0.4 \\
Central nervous system infection & 8 & 4.4 & 0.24 \\
Tumors & 4 & 2.2 & 0.12 \\
Head trauma & 2 & 1.1 & 0.06 \\
Congenital malformations & 1 & 0.5 & 0.03 \\
Unknown & 10 & 5.5 & 0.3 \\
Total & 182 & 100 & 5.45 \\
\hline
\end{tabular}

Abbreviation: PWE, patients with epilepsy. 
Table 5 Rate of different seizure types among various age-groups

\begin{tabular}{|c|c|c|c|c|c|}
\hline Seizure type, n (\%) & $\begin{array}{l}\text { Birth to }<18 \text { years } \\
\mathrm{n}=109\end{array}$ & $\begin{array}{l}\geq 18 \text { to }<\mathbf{4 0} \text { years } \\
n=\mathbf{4 0}\end{array}$ & $\begin{array}{l}\geq 4 \text { to }<60 \text { years } \\
n=20\end{array}$ & $\begin{array}{l}\geq 60 \text { years } \\
n=13\end{array}$ & $\begin{array}{l}\text { Total } \\
\mathrm{N}=182\end{array}$ \\
\hline Generalized & $41(37.6)$ & $22(55.0)$ & $6(30.0)$ & $2(15.4)$ & 7I (38.8) \\
\hline Generalized tonic-clonic & $32(29.4)$ & $21(52.5)$ & $6(30.0)$ & $2(15.4)$ & $61(33.5)$ \\
\hline Tonic & $2(1.8)$ & I (2.5) & $0(0.0)$ & $0(0.0)$ & $3(1.6)$ \\
\hline Clonic & I (0.9) & $0(0.0)$ & $0(0.0)$ & $0(0.0)$ & $\mathrm{I}(0.5)$ \\
\hline Atonic & I (0.9) & $0(0.0)$ & $0(0.0)$ & $0(0.0)$ & $\mathrm{I}(0.5)$ \\
\hline Myoclonic & $2(1.8)$ & $0(0.0)$ & $0(0.0)$ & $0(0.0)$ & $2(1.1)$ \\
\hline Absence & $3(2.8)$ & $0(0.0)$ & $0(0.0)$ & $0(0.0)$ & $3(1.6)$ \\
\hline Focal seizures & $64(58.8)$ & $17(42.5)$ & $14(70.0)$ & II (84.7) & $106(58.3)$ \\
\hline Focal seizures & $4(3.7)$ & $3(7.5)$ & $3(15.0)$ & $2(15.4)$ & $12(6.6)$ \\
\hline $\begin{array}{l}\text { Focal seizures with impaired } \\
\text { consciousness }\end{array}$ & $28(25.7)$ & $10(25.0)$ & $6(30.0)$ & $4(30.8)$ & $48(26.4)$ \\
\hline Focal with secondary generalization & $32(29.4)$ & $4(10.0)$ & $5(25.0)$ & $5(38.5)$ & $46(25.3)$ \\
\hline Mixed & $4(3.7)$ & $\mathrm{I}(2.5)$ & $0(0.0)$ & $0(0.0)$ & $5(2.7)$ \\
\hline
\end{tabular}

Age-specific prevalence rate is at its highest value during early infancy $(12.1 / 1,000)$, gradually decreases during late childhood, and reaches its least value during early adult life $(3.1 / 1,000)$, then increases again during elderly life to reach a second peak $(6.2 / 1,000)$. This U-shaped pattern of agespecific prevalence rate is nearly similar to that reported in developing countries and is consistent with that reported by Banerjee et al, ${ }^{25}$ a finding which may reflect multiple etiologies among persons at the two extremes of life.

Approximately $61 \%$ of PWE reported to have active epilepsy, with a prevalence rate of $3.3 / 1,000$ population. It is lower than the range reported in epidemiological studies in most countries worldwide where it was found to range from 4 to $10 / 1,000$ people. ${ }^{1}$

Incidence varies greatly with age, with highest rates in early infancy, least levels in late childhood, and with a second peak in people aged over 60 years old.

Incidence rate in Al-Quseir $(48 / 100,000)$ lie within the range recorded in developed industrialized countries $(40-70 / 100,000)$ and was lower than that recorded in subSaharan Africa $(63-158 / 100,000) .{ }^{24}$ This may be due to high incidence of symptomatic epilepsy due to CNS infections, mostly neurocysticercosis, in sub-Saharan Africa, which is not encountered in Egypt.

Table 6 Comorbid disorders among PWE in Al-Quseir

\begin{tabular}{lll}
\hline Type of comorbidity & $\mathbf{n}$ & $\%$ \\
\hline Dementia & 9 & 4.9 \\
Mental retardation & 51 & 28 \\
Psychosis & 3 & 1.6 \\
Substance abuse & 2 & 1.1 \\
Cerebral palsy & 15 & 6.6 \\
Stroke & 12 & 8.3 \\
Total & 92 & 50.5 \\
\hline
\end{tabular}

Abbreviation: PWE, patients with epilepsy.
The two major categories of seizure type classified by the $\mathrm{ILAE}^{10}$ are epilepsy characterized by focal seizures and epilepsy characterized by generalized seizures. The exact aetiology is unclear however, and in some cases are still unknown. ${ }^{25}$

Generally, the median rates are higher for focal than for generalized seizures, but this difference usually is not significant. ${ }^{26}$

The median incidence rate of focal seizures is higher in children (de Bittencourt et al) than in adults (ILAE, 1996). ${ }^{9}$ In our study, focal seizures were recorded in higher rates both in childhood (58.7\%), late adulthood (70\%), and in the elderly (84.6\%). This may be attributed to the high incidence of symptomatic epilepsy due to CNS insults, whether perinatal complications in childhood or vascular insults in late adulthood, and elderly personnel.

In this study, generalized seizures were $39 \%$ while focal seizures were $58.2 \%$. These results are consistent with studies worldwide where Peichev et al in Chile ${ }^{27}$ found that the rate of focal seizures was $55 \%$ and in India it was $54 \%$ as recorded by Bharucha et al. ${ }^{28}$

Regarding seizure semiology, the commonest types of seizures were primary generalized tonic-clonic seizure (33.5\%) followed by focal seizures associated with impaired consciousness (26.4\%) and focal seizures with secondary generalization $(25.3 \%)$.

Structural/metabolic causes of epilepsy were recorded in $31.9 \%$ and this was consistent with that recorded in Rochester, MN, USA $(35 \%)^{22}$ and in most Asian countries in which it ranged from $22 \%$ to $53 \% .{ }^{15}$

It was found that perinatal complications were the most common causes (17\% of PWE) with a prevalence of $0.9 / 1,000$ of total inhabitants. This is consistent with the findings of Kapoor et $\mathrm{al}^{29}$ which found that delivery-related trauma and CNS infections are the most common causes of 
Table 7 Rate of active epilepsy and treatment gap in Al-Quseir

\begin{tabular}{lll}
\hline Subject & $\mathbf{n}$ & Rate (\%) \\
\hline Patients with active epilepsy & $1 \mathrm{II/182}$ & 61.0 \\
Prevalence rate of active epilepsy/I,000 population & & $3.3 / 1,000$ \\
Patients with active epilepsy on regular AEDs & 18 & 16.2 \\
Patients with active epilepsy never received AEDs & 28 & 25.2 \\
Patients with active epilepsy who are inadequately treated & 65 & 58.6 \\
Treatment gap & $93 / 111$ & 83.8 \\
\hline
\end{tabular}

Abbreviation: AED, anti-epileptic drug.

symptomatic epilepsy. This may draw our attention to lack of perinatal care in this area, which is far away from basic medical services.

The lifetime prevalence rate of epilepsy was higher among males $(6.8 / 1,000)$ than females $(4.1 / 1,000)$, but the difference was statistically insignificant.

This is consistent with meta-analysis of 16 out of 29 door-to-door studies and eleven out of 16 record-review studies which showed that males are more affected than females..$^{25}$ The most extreme example of a male excess was reported in a study conducted in India, in which prevalence of males with epilepsy $(5.1 / 1,000)$ was significantly higher than females $(2.2 / 100) .{ }^{28}$ In this population, women with epilepsy are considered unmarriageable and this may have led to active concealment of symptoms or diagnosis among women. However, absolute difference in sex-specific prevalence is minimal.

Positive consanguineous marriage was reported among parents of $8.2 \%$ of parents of people with epilepsy. Furthermore, an extra $11 \%$ of people with epilepsy patients reported positive grandparent's consanguinity.

Moreover, $9.8 \%$ of our patients had positive family history of epilepsy among first-degree relatives. It is higher than that reported by ${ }^{29}$ where $5.2 \%$ of the patients had a family history of epilepsy among first-degree relatives, and this was a comparable rate in relation to other factors, such as perinatal complications (5.2\%) and CNS accidents (5.2\%).

A long and a rich history of research has characterized relationships between cognitive status and a variety of clinical factors related to epilepsy, including underlying etiology, age of onset, seizure type and severity, duration, antiepileptic medications, and other factors. ${ }^{30}$ The nature, timing, and course of cognitive impairment in epilepsy are issues of substantial concern, particularly the degree to which chronic, medication-resistant epilepsy may lead to progressive cognitive impairment. ${ }^{31}$

Moreover, an essential relationship has been documented between epilepsy and a host of developmental, cognitive, behavioral, and psychiatric disorders. These consequences reflect the fact that epilepsy is a disorder of brain function, not just a disorder that produces seizures. ${ }^{3}$

To evaluate the impact of epilepsy on cognitive abilities we looked at a cognitive assessment for our patients. An International Bureau for Epilepsy (IBE) conducted survey on cognitive functions of 425 patients with epilepsy, showed that $44 \%$ of patients with epilepsy complained of difficulty in learning, $45 \%$ thought that they are slow thinkers, and $63 \%$ thought that the drugs may affect their abilities to do activities or to achieve goals. ${ }^{32}$

In this study, $28 \%$ of patients with epilepsy were mentally subnormal, and $36.3 \%$ of cases were illiterate or just read and write in comparison to $15.6 \%$ only in the general population. Only $1.1 \%$ of patients with epilepsy joined university in comparison to $15.6 \%$ of the general population.

Epilepsy also has an impact on the working abilities of patients in this study, where $51.7 \%$ of patients with epilepsy were unemployed in comparison to $23.7 \%$ of the general population, and $8.8 \%$ of them were housewives in comparison to $19.4 \%$ of general population. Furthermore, only 3.3\% of PWE were working in mental-related work in comparison to $11.4 \%$ of the general population.

Table 8 Magnitude of treatment gap worldwide

\begin{tabular}{llll}
\hline Location & Studies (n) & Treatment gap (\%) & Author \\
\hline Al-Quseir/present study & $\mathrm{I}$ & 83.8 & El-Tallawy et al $^{4}$ \\
Al-Kharga, Egypt & $\mathrm{I}$ & 58.9 & $\mathrm{El-Tallawy} \mathrm{et} \mathrm{al}^{38}$ \\
Asia and Africa & 65 & 56 & $\mathrm{Ngugi}^{\text {et al }}$ \\
Rural Vietnam & $\mathrm{I}$ & 84.7 & Tuan et al $^{40}$ \\
Brazil & $\mathrm{I}$ & 56.6 & $\mathrm{Noronha} \mathrm{et} \mathrm{al}^{41}$ \\
Rural China & $\mathrm{I}$ & 49.8 & Wang et al $^{42}$ \\
\hline
\end{tabular}




\section{Treatment gap}

Population-based data about medical treatment of active epilepsy are scarce. On the other hand, significant differences between similar studies probably also reflect general treatmentrelated concepts among local physicians and patients. ${ }^{33,34}$

In many developing countries, people with epilepsy do not receive appropriate treatment for their condition, a phenomenon called the treatment gap. ${ }^{35}$

The determination of epilepsy treatment gap (ie, the number of people with active epilepsy who have not received biomedical services or who are not on treatment or are on inadequate treatment) is vital for health care planning, both on a public health level as well as an individual level. This treatment gap is a major cause of suffering and death and contributes to the socioeconomic burden of the disease. ${ }^{36}$

Treatment gap in Al-Quseir reaches 83.8\%. This is consistent with that reported by ILAE/The International Bureau for Epilepsy/World Health Organization in their introduction to the Global Campaign against Epilepsy, "Epilepsy out of the Shadows", where they stated that globally $85 \%$ of people with epilepsy are either inappropriately treated or not treated at all. ${ }^{37}$

Meta-analysis of 27 studies, 12 from Africa, nine from Asia, and six from Latin America, revealed that the overall estimate of the treatment gap was 56/100 (95\% confidence interval 31.1-100.0). ${ }^{35}$

It is less than that reported in the current study in Al-Quseir. The variation in estimates could possibly be explained by nonuniform treatment gap estimation methods, different definitions of active epilepsy, and diverse study populations, among other factors. The treatment gap was mainly attributed to inadequately skilled manpower, cost of treatment, cultural beliefs, and unavailability of anti-epileptic drugs. ${ }^{35}$

\section{Conclusion}

The lifetime prevalence of epilepsy in Al-Quseir was 5.5/1,000 population, with peak prevalence during early childhood. The life time prevalence of epilepsy in Al-Quseir city, Red Sea Governorate, was 5.5/1,000. The peak prevalence occurred during early childhood. The annual incidence rate of epilepsy was $48 / 100,000$, with highest peaks occurring during early infancy and elderly and the least prevalent was during early adulthood (61\%). Approximately, two third of PWE ( $n=111)$ have active epilepsy (the most recent seizure is within in the previous 5 years) with a total prevalence rate was $3.3 / 1,000$. The treatment gap of patients with active epilepsy was $83.8 \%$.
Epilepsy is not just one disorder. It affects cognitive, physical, and social aspects of the individual who needs more care from society especially in areas away from medical services.

\section{Disclosure}

The authors report no conflicts of interest in this work.

\section{References}

1. Sander JW. The epidemiology of epilepsy revisited. Curr Opin Neurol. 2003;16:165-170.

2. Brodie MJ, Kwan P. Epilepsy in elderly people. BMJ. 2005;331: 1317-1322.

3. Linehan C, Tellez-Zenteno JF, Burneo JG, Berg AT. Future directions for epidemiology in epilepsy. Epilepsy Behav. 2011;22:112-117.

4. El-Tallawy H, Farghaly W, Metwally N, et al. Prevalence of neurological disorders in Al Quseir, Egypt: methodological aspects. Neuropsychiatr Dis Treat. 2013;9:1295-1300.

5. El Tallawy HN, Farghaly WM, Metwaly NA, et al. Door-to-door survey of major neurological disorders in Al Kharga District, New Valley, Egypt: methodological aspects. Neuroepidemiology. 2010;35: 185-190.

6. Tallawy HN, Farghaly WM, Rageh TA, et al. Door-to-door survey of major neurological disorders (project) in Al Quseir City, Red Sea Governorate, Egypt. Neuropsychiatr Dis Treat. 2013;9:767-771.

7. Melika LK. The Stanford-Binet Intelligence Scale, 4th ed. Cairo: Dar El-Maref; 1998.

8. Delany EA, Hopkins TF. The Stanford. Binet Intelligence Scale: Examiners Handbook, 4 ed. Chicago: The Riverside Publishing Co. Revised; 1986.

9. de Bittencourt PR, Adamolekum B, Bharucha N, et al. Epilepsy in the tropics: I. Epidemiology, socioeconomic risk factors, and etiology. Epilepsia. 1996;37:1121-1127.

10. de Bittencourt PR, Adamolekum B, Bharucha N, et al. Epilepsy in the tropics: II. Clinical presentations, pathophysiology, immunologic diagnosis, economics, and therapy. Epilepsia. 1996;37:1128-1137.

11. Liu YM, Williams S, Basualdo-Hammond C, Stephens D, Curtis R. A prospective study: growth and nutritional status of children treated with the ketogenic diet. J Am Diet Assoc. 2003;103:707-712.

12. Khan GM, Smolders I, Ebinger G, Michotte Y. Anticonvulsant effect and neurotransmitter modulation of focal and systemic 2-chloroadenosine against the development of pilocarpine-induced seizures. Neuropharmacology. 2000;39:2418-2432.

13. Schmidt D, Bourgeois B. A risk-benefit assessment of therapies for Lennox-Gastaut syndrome. Drug Saf. 2000;22:467-477.

14. Fernandes PT, Salgado PC, Noronha AL, et al. Epilepsy stigma perception in an urban area of a limited-resource country. Epilepsy Behav 2007; 11:25-32.

15. Mac TL, Tran DS, Quet F, Odermatt P, Preux PM, Tan CT. Epidemiology, aetiology, and clinical management of epilepsy in Asia: a systematic review. Lancet Neurol. 2007;6:533-543.

16. Nolan MA, Redoblado MA, Lah S, et al. Intelligence in childhood epilepsy syndromes. Epilepsy Res. 2003;53:139-150.

17. Nunes VD, Sawyer L, Neilson J, Sarri G, Cross JH. Diagnosis and management of the epilepsies in adults and children: summary of updated NICE guidance. BMJ. 2012;344:e281.

18. Sander JW, Shorvon SD. Epidemiology of the epilepsies. J Neurol Neurosurg Psychiatry. 1996;61:433-443.

19. Jallon P. Epilepsy in developing countries. Epilepsia. 1997;38: 1143-1151.

20. Kelvin EA, Hesdorffer DC, Bagiella E, et al. Prevalence of self-reported epilepsy in a multiracial and multiethnic community in New York City. Epilepsy Res. 2007;77:141-150. 
21. Khedr EM, Shawky OA, Ahmed MA, et al. A community based epidemiological study of epilepsy in Assiut Governorate/Egypt. Epilepsy Res. 2013;103:294-302.

22. Hauser WA, Annegers JF, Kurland LT. Incidence of epilepsy and unprovoked seizures in Rochester, Minnesota: 1935-1984. Epilepsia. 1993;34:453-468

23. Jallon P. Epilepsy and epileptic disorders, an epidemiological marker? Contribution of descriptive epidemiology. Epileptic Disord. 2002;4:1-13.

24. Preux PM, Druet-Cabanac M. Epidemiology and aetiology of epilepsy in sub-Saharan Africa. Lancet Neurol. 2005;4:21-31.

25. Banerjee PN, Filippi D, Allen Hauser W. The descriptive epidemiology of epilepsy - a review. Epilepsy Res. 2009;85:31-45.

26. Kotsopoulos IA, van Merode T, Kessels FG, de Krom MC, Knottnerus JA. Systematic review and meta-analysis of incidence studies of epilepsy and unprovoked seizures. Epilepsia. 2002;43:1402-1409.

27. Peichev L, Marazova K. Epidemiological study of the frequency of prescribing antiepileptic drugs. Folia Medica. 1992;34:8-13.

28. Bharucha NE, Bharucha EP, Bharucha AE, Bhise AV, Schoenberg BS. Prevalence of epilepsy in the Parsi community of Bombay. Epilepsia. 1988;29:111-115.

29. Kapoor A, Satishchandra P, Ratnapriya R, et al. An idiopathic epilepsy syndrome linked to $3 \mathrm{q} 13.3-\mathrm{q} 21$ and missense mutations in the extracellular calcium sensing receptor gene. Ann Neurol. 2008;64:158-167.

30. Jokeit H, Ebner A. Effects of chronic epilepsy on intellectual functions. Prog Brain Res. 2002;135:455-463.

31. French J, Friedman D. Epilepsy: from newly diagnosed to treatmentresistant disease. Lancet Neurol. 2011;10:9-11.

32. Fisher RS, van Emde Boas W, Blume W, et al. Epileptic seizures and epilepsy: definitions proposed by the International League Against Epilepsy (ILAE) and the International Bureau for Epilepsy (IBE). Epilepsia. 2005;46:470-472.
33. Oun A, Haldre S, Magi M. Incidence of adult epilepsy in Estonia. Acta Neurol Scand. 2003;108:245-251.

34. Oun A, Haldre S, Magi M. Prevalence of adult epilepsy in Estonia. Epilepsy Res. 2003;52:233-242.

35. Mbuba CK, Ngugi AK, Newton CR, Carter JA. The epilepsy treatment gap in developing countries: a systematic review of the magnitude, causes, and intervention strategies. Epilepsia. 2008;49:1491-1503.

36. Newton CR, Garcia HH. Epilepsy in poor regions of the world. Lancet. 2012;380:1193-1201.

37. Meinardi H, Scott RA, Reis R, Sander JW; ILAE Commission on the Developing World. The treatment gap in epilepsy: the current situation and ways forward. Epilepsia. 2001;42:136-149.

38. El-Tallawy HN, Farghaly WM, Shehata GA, et al. Epidemiology of epilepsy in New Valley Governorate, Al Kharga District, Egypt. Epilepsy Res. 2013;104:167-174.

39. Ngugi AK, Bottomley C, Kleinschmidt I, Sander JW, Newton CR. Estimation of the burden of active and life-time epilepsy: a meta-analytic approach. Epilepsia. 2010;51:883-890.

40. Tuan NA, Tomson T, Allebeck P, Chuc NT, Cuong le Q. The treatment gap of epilepsy in a rural district of Vietnam: a study from the EPIBAVI project. Epilepsia. 2009;50:2320-2323.

41. Noronha AL, Borges MA, Marques LH, et al. Prevalence and pattern of epilepsy treatment in different socioeconomic classes in Brazil. Epilepsia. 2007;48:880-885.

42. Wang W, Wu J, Dai X, et al. Global campaign against epilepsy: assessment of a demonstration project in rural China. Bull World Health Organ. 2008;86:964-969.
Neuropsychiatric Disease and Treatment

\section{Publish your work in this journal}

Neuropsychiatric Disease and Treatment is an international, peerreviewed journal of clinical therapeutics and pharmacology focusing on concise rapid reporting of clinical or pre-clinical studies on a range of neuropsychiatric and neurological disorders. This journal is indexed on PubMed Central, the 'PsycINFO' database and CAS,

\section{Dovepress}

and is the official journal of The International Neuropsychiatric Association (INA). The manuscript management system is completely online and includes a very quick and fair peer-review system, which is all easy to use. Visit http://www.dovepress.com/testimonials.php to read real quotes from published authors. 